\title{
Promising international interventions and treatment for women who use and abuse drugs: focusing on the issues through the InWomen's Group
}

\author{
This article was published in the following Dove Press journal: \\ Substance Abuse and Rehabilitation \\ 27 January 2012 \\ Number of times this article has been viewed
}

\author{
Wendee M Wechsberg ${ }^{1-4}$ \\ 'Substance Abuse Treatment \\ Evaluations and Interventions \\ Research Program, RTI International, \\ Research Triangle Park; ${ }^{2}$ Gillings \\ Global School of Public Health, \\ University of North Carolina at \\ Chapel Hill; ${ }^{3}$ Psychology in the \\ Public Interest, North Carolina State \\ University, Raleigh; ${ }^{4}$ Psychiatry and \\ Behavioral Sciences, Duke University \\ School of Medicine, Durham, NC, \\ USA
}

Correspondence: Wendee M Wechsberg Senior Director, Substance Abuse Treatment Evaluations and Interventions Research Program, RTI International, 3040 Cornwallis Rd, Research Triangle Park, NC 27709-2194 USA

$\mathrm{Tel}+|91954| 6422$

Fax + I 9194855555

Emailwmw@rti.org
Globally, an estimated 205 million people use illicit drugs and among them 25 million people are drug dependent. ${ }^{1,2}$ Although women do not constitute the majority of all alcohol and other drug users, substance use has been steadily increasing among women and particularly among young women. ${ }^{2-5}$ Furthermore, with a few exceptions, the majority of research on women's substance abuse, interventions, and treatment has been conducted in North America, Australia, and European countries. ${ }^{5}$ Thus, the findings from these studies are likely not representative of all female drug users worldwide. ${ }^{2,3}$

Women are child-bearers, so reaching them and offering harm reduction and/or treatment will not only help them but also their families and future generations. ${ }^{6}$ In addition, many countries do not have treatment that is designated for women who use drugs, nor is this treatment typically sensitive to the contextual factors that intersect with drug use and risk and reinforce women's vulnerability. ${ }^{7-9}$

Recent studies show that women who use or abuse substances are more at risk of being raped, physically assaulted and robbed, and more likely to contract human immunodeficiency virus (HIV). ${ }^{10,11}$ In addition, in many settings around the world, vulnerable women who use drugs often face a further challenge of stigmatization from health care providers. ${ }^{12}$ Unmet health care needs and basic inequality manifest in women's vulnerability to greater victimization, more severe substance dependence, and disease, especially HIV/acquired immunodeficiency syndrome (AIDS). ${ }^{12}$

The United Nations 2015 Millennium Development Goal 3 (to promote gender equality and empower women) and Goal 5 (to improve maternal health) are still largely unmet. ${ }^{13}$ Consequently, many women remain marginalized and vulnerable. And because they lack equity and equality, these women are underserved.

Researchers and health providers worldwide are concerned about the continuing unaddressed gender inequities, the contextual and cultural compromises, and the comorbidities that often plague women who use illicit drugs. ${ }^{3,14,15}$ From drug use initiation to abuse, key questions remain unanswered. For example, why do women start using drugs? Who initiates women into drug use? Why do so many women continue to use drugs? How do sexual risk and gender-based violence interact? How does this interface 
often lead to the defilement of women and girls, especially in war-torn and poverty-stricken regions?

Further, women are frequently caught in cultural roles with gender-based expectations and they do not know how or where to access treatment, or to go to treatment without being stigmatized and ostracized within their communities, or to find programs that are specifically woman-focused and sensitive to their needs.

To begin to address many of these aspects of and consequences stemming from women's substance use and abuse, the International Women's and Children's Health and Gender Group (InWomen's Group) was established in 2007. The InWomen's Group mission is to maintain a multidisciplinary forum that addresses all aspects of the consequences of substance use. The forum members aim to share findings about the consequences of substance use, abuse, and risk behaviors, and the benefits of prevention, intervention, and treatment; maintain sensitivity to family, culture, and equity within an international context; forge future collaborations and research agendas; and identify additional activities to promote successful and empowering research with these vulnerable populations across their lifespan. Over the past 4 years, the InWomen's Group has been building momentum within the international drug abuse research community, as evidenced by our nearly 200 members from 35 countries.

Since its inception, the InWomen's Group has held an annual conference where scientists, clinicians, students, and substance abuse professionals come together to advance addiction research by integrating concepts and methodologies that focus on women and substance abuse from a feminist perspective. The annual InWomen's Conference aims to address issues of substance abuse and the intersecting risks of HIV, contextual issues, and comorbidity among women substance abusers around the world. Another aim is to encourage researchers to become more involved with the unique needs of women and to investigate and eliminate the barriers many women face when attempting to obtain comprehensive HIV prevention, treatment, and care.

Despite the fact that substance use is increasing among women internationally, there are few evidence-based, womanfocused interventions and treatment programs available. Those that do exist are struggling to survive within today's dire economic environment. Consequently, the annual InWomen's Conference focuses attention on the critical need for expanding women's substance abuse research, interventions, and treatment on an international scale. These annual meetings have become an important forum to share knowledge and products, to network, to foster next-generation thinking, and to initiate new collaborations between established researchers and those new to the field.

The InWomen's Group and annual conference have opened the lines of communication across diverse multidisciplinary academic fields, and we have begun to address women's complex substance abuse and health care issues. Because of the many diverse topics associated with women's substance abuse, the InWomen's Group has established and maintains a virtual library to address as many issues as possible with the most up-to-date literature on each topic. ${ }^{16}$

In addition, through the InWomen's Conference findings, we disseminate our roundtable discussions in each topical area along with the relevant research to stimulate the development of multinational collaborations and substance abuse research agendas. These activities are accessible through a Web-based collaboratory meeting and associated published literature that is updated each year and organized under areas of concentration. These summaries from conference group discussions are posted in our Wiki, along with the conference presentations.

This special issue of Substance Abuse and Rehabilitation represents another important dissemination avenue for recent InWomen's findings. This collection of seven recent papers from our speakers and members reflects our commitment to push the research envelope of what we know about women who use substances, their diversity, the contextual factors affecting their lives, their needs, the treatment barriers they face, ${ }^{6}$ and next steps with regard to interventions and treatment.

Maayan Schori and colleagues describe a small-scale study and report that women with more comorbidities may stay in treatment if they are supported early on in treatment settings and that long-term woman-focused residential treatment demonstrates positive outcomes in Israel.

In an important large international multisite trial, Sharon Wilsnack shows that different levels of alcohol use and abuse exist with partners and without partners and by gender. She also presents levels of use not commonly thought of for women, especially with traditionally abstinent and older women. Wilsnack's findings are similar to other studies with women who have been victimized by partners and are heavy drug users. Her research suggests that women are starting to drink in countries experiencing rapid social change. Consequently, social marketing about the hazards of drinking along with social and economic empowerment is needed for these women. 
Ingunn Lund and colleagues share their findings from the Maternal Opioid Treatment Human Experimental Research (MOTHER) study and provide an initial assessment of the relative efficacy of comparing methadone with detoxification only and comparing buprenorphine with detoxification only in terms of neonatal and maternal delivery outcomes.

Sally Stevens addresses the importance of moving from research to practice to meet the special treatment needs of lesbian, bisexual, and transgender women. She reviews the findings from previous studies, presents new data collected from community-based and residential substance abuse treatment programs, and offers new recommendations for tailoring substance abuse treatment programs to meet the specific needs of this population.

Jamila Stockman and colleagues examine behavior change theories and models that include an empowerment framework and biomedical models. These have either been integrated or could be integrated into HIV prevention intervention efforts for drug-using women with histories of partner violence. However, they report that none of these theories and models are all-inclusive of the needs for women with risk behaviors.

Jennifer Johnson and colleagues present the results of a South African study with vulnerable women who use drugs and they compare women who have been involved with the criminal justice system with women who have not. They demonstrate the greater needs among women who have been involved with the criminal justice system and address the implications for specialized interventions for these women.

Kate Dolan and colleagues conducted a small study that yielded the first evidence of Iranian female drug users who entered methadone treatment and were followed over time. The findings showed that these women reduced heroin use, decreased their levels of dependence, improved social functioning, and reduced their HIV risk.

Along with these important scientific contributions to the field, the larger community of InWomen feminist researchers has a mission to continue to support promising interventions and treatment for women and to honor the diversity of needs as well as individual and cultural differences. Our overarching goal is to build a global network of support and establish best practices guidelines internationally for women who use drugs and are in need of woman-focused interventions and treatment. Ultimately, through policy change we hope to raise awareness of women's issues and the need for greater equity and equality in the larger scheme of women's treatment, and to create more efficacious opportunities for vulnerable women to improve their lives and the lives of their families.

\section{Acknowledgements/Disclosure}

This work was supported by RTI International as part of the author's role as Chair of the InWomen's Group. The author gratefully acknowledges Dr LiTzy Wu for her feedback on this introduction and her overall support for this special issue of Substance Abuse and Rehabilitation comprising papers from the 2011 InWomen's Conference and its members. The author also would like to thank Jeff Novey, Winona Poulton, and Julianne Foster for their assistance. No conflict of interest is noted. The interpretations and conclusions presented in this paper are solely those of the author.

\section{References}

1. United Nations Office on Drugs and Crime (UNODC) and World Health Organization. UNODC-WHO joint programme on drug dependence treatment and care. May 2009. Available from: http://www. unodc.org/docs/treatment/09-82847_Ebook_ENGLISH.pdf. Accessed October 21, 2011.

2. United Nations Office on Drugs and Crime (UNODC). Drug abuse among women: emerging global trends. May 6, 2003. Available from: http://www.unodc.org/pdf/india/publications/women_Book-6-503/12_drugabuseamongwomen-emergingglobaltrends.pdf. Accessed October 21, 2011.

3. United Nations Office on Drugs and Crime. Substance abuse treatment and care for women: Case studies and lessons learned. Aug 2004 Available from: http://www.unodc.org/pdf/report_2004-2008-30_1. pdf. Accessed October 21, 2011.

4. Center for Substance Abuse Treatment. Substance Abuse Treatment: Addressing the Specific Needs of Women. Treatment Improvement Protocol (TIP) Series 51. HHS Publication No. (SMA) 09-4426. Rockville, MD: Substance Abuse and Mental Health Services Administration; 2009. Available from: http://kap.samhsa.gov/products/manuals/tips/ pdf/TIP51.pdf. Accessed October 21, 2011.

5. Wechsberg WM, Wu L, Zule WA, et al. Substance abuse, treatment needs and access among female sex workers and non-sex workers in Pretoria, South Africa. Subst Abuse Treat Prev Policy. 2009;4(11): $1-11$.

6. Wechsberg WM, Luseno W, Ellerson RM. Reaching women substance abusers in diverse settings: stigma and access to treatment 30 years later. Subst Use Misuse. 2008;43(8-9):1277-1279.

7. Wechsberg WM, Luseno W, Riehman K, Karg R, Browne F, Parry C. Substance use and sexual risk within the context of gender inequality in South Africa. Subst Use Misuse. 2008;43:1186-1201.

8. Riehman KS, Wechsberg WM, Zule WA, Lam WK, Levine BA. Gender differences in the impact of social support on crack use among AfricanAmericans. Subst Use Misuse. 2008;43(1):85-104.

9. Wechsberg WM, Lam WK, Zule W, Hall G, Middlesteadt R, Edwards J. Violence, homelessness, and HIV risk among crack-using AfricanAmerican women. Subst Use Misuse. 2003;38:671-701.

10. Wechsberg WM, Luseno WK, Lam WK. Violence against substanceabusing South African sex workers: intersection with culture and HIV risk. AIDS Care. 2005;17(Suppl 1):S55-S64. 
11. Parry C, Petersen P, Carney T, Dewing S, Needle R. Rapid assessment of drug use and sexual HIV risk patterns among vulnerable drugusing populations in Cape Town, Durban and Pretoria, South Africa. SAHARA J. 2008;5(3):113-119.

12. Luseno WK, Wechsberg WM, Kline TL, Ellerson RM. Health services utilization among South African women living with HIV and reporting sexual and substance-use risk behaviors. AIDS Patient Care STDs. 2010;24:257-264.

13. United Nations 2015 Millennium Development Goals. Department of Public Information, United Nations. 2010. Available from: http://www. un.org/millenniumgoals/. Accessed October 21, 2011.
14. Wechsberg WM, Luseno W. The need for culturally appropriate, genderspecific global HIV prevention efforts with vulnerable women. J Prev Interv Community. 2010;38(2):85-88.

15. Pinkham S, Malinowska-Sempruch K. Women, Harm Reduction, and $H I V$. New York, NY: International Harm Reduction Development Program of the Open Society Institute. 2007. Available from: http://www. soros.org/initiatives/health/focus/ihrd/articles_publications/publications/ women_20070920/women_20070920.pdf. Accessed October 21, 2011.

16. NIDA International Virtual Collaboratory. International Women's and Children's Health and Gender Group. 2011. Available from: http://nivc. perpich.com/groups/inwomen/dashboard. Accessed October 21, 2011.

\section{Publish your work in this journal}

Substance Abuse and Rehabilitation is an international, peer-reviewed, open access journal publishing original research, case reports, editorials, reviews and commentaries on all areas of addiction and substance abuse and options for treatment and rehabilitation. The manuscript management system is completely online and includes a very quick and fair peer-review system. Visit http://www.dovepress.com/testimonials.php to read real quotes from published authors. 